\title{
Cultura Cultura
}

Revistade historia e Teria das ldeais $\quad$ Revista de História e Teoria das Ideias

vol. $21 \mid 2005$

Livro e Iconografia

\section{Ver e ler}

\section{João Luís Lisboa}

\section{OpenEdition}

Journals

\section{Edição electrónica}

URL: http://journals.openedition.org/cultura/2788

DOI: $10.4000 /$ cultura. 2788

ISSN: 2183-2021

\section{Editora}

Centro de História da Cultura

\section{Edição impressa}

Data de publição: 1 janeiro 2005

Paginação: 7-12

ISSN: 0870-4546

\section{Refêrencia eletrónica}

João Luís Lisboa, « Ver e ler », Cultura [Online], vol. 21 | 2005, posto online no dia 21 maio 2016, consultado a 24 setembro 2020. URL : http://journals.openedition.org/cultura/2788 ; DOI : https:// doi.org/10.4000/cultura.2788

Este documento foi criado de forma automática no dia 24 setembro 2020.

(c) CHAM - Centro de Humanidades / Centre for the Humanities 


\title{
Ver e ler
}

\author{
João Luís Lisboa
}

Imagens e textos cruzam-se e encontram-se (ou desencontram-se) de muitas formas. Tenhamos presente as grandes narrativas que se partilham oralmente e que têm referentes visuais nos templos, nos palácios e nas ruas, tanto em suportes efémeros, em festas e procissões, como permanentes. Também nos livros, lugar de letras por definição, vê-se para além do que se lê. Ou lê-se para além das letras. Lê-se na composição, na disposição das páginas, na textura do papel ou das peles, no aparato ou na falta dele, nas gravuras, sejam ornamento ou parte integrante da narrativa. Porventura essas gravuras reproduzem cenas e personagens que já se conhecem das igrejas e das ruas. Pensar o livro é, assim, como diz Henri-Jean Martin, pensar uma peça de um processo de comunicação.

Ao longo dos séculos, e sobretudo a partir de setecentos, à medida que a cultura escrita sai dos livros e passa a ocupar os espaços urbanos, na identificação dos locais, na organização do quotidiano, tornando-se necessária, e não um recurso especializado de quem precisa de exercer certas actividades, a imagem vai ganhando mais espaço no mundo impresso, equilibrando um estatuto que pertencia sobretudo à palavra.

De que falam as representações que nos aparecem impressas e encadernadas? das palavras que acompanham? repetem-nas? comentam-nas como um coro que sublinha certas passagens? Entre os vários olhares possíveis, escolhemos considerá-las na sua autonomia relativa, corno várias vozes que se encontram para cumprir funções próprias.

Não pensamos a imagem impressa como subordinada a textos. Mas também não a vemos como testemunho isolado da evolução de técnicas e valores estéticos. A imagem faz passar sentido. Tem códigos próprios e assenta num saber fazer (de quem desenha, grava ou imprime) e num saber ler (do conjunto daqueles a quem se destina). A imagem existe nos suportes que lhe dão corpo, relacionando-se: (1) com as possibilidades de leitura que esses suportes permitem ou sugerem; (2) com outras linguagens que lhes estão próximas; (3) com outras imagens que os leitores viram ou conhecem. A imagem fixa a atenção em personagens ou episódios. Enfatiza momentos de uma narrativa. Confere estatuto ao próprio suporte, pela sua elaboração ou riqueza. Finalmente, a 
imagem é feita para causar impressões, para sugestionar, para atrair, para contar de outro modo.

A imagem ilustra, não necessariamente no sentido que lhe damos hoje, de estampa ou desenho, associado a um texto, mas no de "tornar claro e evidente" que é o sentido de Bluteau em 1713. A imagem integra os recursos da retórica, ao "mover afectos" e ao "tornar inteligível" um discurso. Tem valor enquanto representação, independentemente de apoiar ou de se apoiar em textos. Implica "decoro" e não decoração. Que possa ornar no sentido de embelezar é apenas uma das suas funções. Falamos, assim, de iconografia, e não de ilustração.

O modo como a imagem foi existindo nos livros ou em estampas soltas tem uma história com referências. As mais importantes continuam a ser os trabalhos de Ernesto Soares. É de salientar o Dicionário de iconografia portuguesa, em 5 volumes (1947-1960), que começou a publicar com Henrique Ferreira Lima, entretanto falecido. Hoje, esses trabalhos, embora manifestamente insuficientes, seja pelas naturais lacunas que o tempo revela, seja pela sua perspectiva datada, continuam a ser muito úteis. Para além de extenso inventário, o que devemos reter para os períodos mais remotos? Desde logo, o facto de a grande maioria das gravuras terem os livros como destino. Também o facto de quase não haver identificação dos gravadores antes do século XVIII. Finalmente, Ernesto Soares fornece algumas razões para a diferença entre a produção ibérica e a do centro e norte da Europa: "a pequena produção do livro, obrigado a ilustração artística, a escassez de um mercado compensador e, especialmente, o nosso temperamento nada sujeito a trabalhos, para o que se exigia uma sedentariedade enervante, são motivos que explicam o atrazo neste ramo da arte" (Evolução da gravura em madeira em Portugal nos séculos XV a XIX, Lisboa, CML, 1951, p.6). A questão do temperamento do "guerreiro, navegador e aventureiro" pode hoje provocar um sorriso, mas importa pensar que a história da gravura é parte da história (social e cultural) mais ampla de como se fazem circular ideias, sentimentos, narrativas. Nessa história compreendem-se nomes (de impressores e gravadores, por exemplo), segue-se a transformação de técnicas, gostos, custos, procura-se o modo como cresce o número de leitores e a variedade das suas características.

Se nunca existe um leitor abstracto e uniforme de textos idealizados, a diversidade dos leitores acentua-se com a multiplicação das formas do que se dá a ler, incluindo na relação entre texto e imagem. No caso dos almanaques de seiscentos e setecentos, pequenos ícones podem ser o fio condutor do olhar de quem quer perceber as fases da lua, ou a sucessão zodiacal. Há pois a necessidade de chegar a um público que não convive quotidianamente com páginas escritas.

Pelo contrário, o aparato da representação do poder nas xilogravuras do De vita Christi (1495) constitui um discurso paralelo ao do texto, como se se pudesse ler a piedade da Coroa nas letras, e a devoção do rei nas imagens. Refiro não apenas a representação dos soberanos em adoração ou as suas divisas, mas todo o cuidado iconográfico que é condicionado pela encomenda. Pode até considerar-se que não existe uma relação biunívoca entre as duas linguagens e que, paradoxalmente, uma leitura possível sugere que é o texto que "ilustra" o que se vê. Na cópia manuscrita do mosteiro de Alcobaça, ou nos fragmentos em latim que existem em Évora, ambos anteriores em cerca de meio século ao incunábulo, as iniciais filigranadas a cores e as cercaduras filigranadas marcam ritmos de leitura e sublinham a importância do livro (como, no impresso, as capitulares e os sinais de parágrafos), sem introduzir nenhuma interferência no texto 
de Ludolfo de Saxónia. Já o livro impresso vem fazer duas afirmações que são novas para o tempo em Portugal, ambas ligadas à possibilidade de a tipografia produzir livros como aqueles que já se conheciam antes. Primeiro, que o livro impresso não é apenas um expediente de cópia, mas pode ser um cuidadoso objecto de aparato. Segundo, que o poder se identifica com o novo produto, o usa e nele se revê.

Seguir os impressores do De vita Christi é ver outros usos das mesmas gravuras, como faz Nicolau de Saxónia ao reproduzir uma excepcional (e possivelmente não produzida em Portugal) imagem do calvário no Missale Bracharense, em 1498, ou é confirmar a importância de uma oficina como a de Valentim Fernandes, que multiplica as xilogravuras nos seus trabalhos posteriores, a começar pelas também excepcionais representações na Grammatica Pastranae (1497) e na Estoria de muy nobre Vespesiano (1496). Ainda quanto a esta novela, Artur Anselmo chamou a atenção para a flagrante semelhança entre uma das suas xilogravuras, relativa ao massacre dos Judeus, e uma outra publicada poucos anos depois por Pedro Brun, em 1499, em Sevilha, no terceiro dos incunábulos peninsulares dedicados à novela (História da edição em Portugal, Porto, Lello \& irmão, 1991, pp.168-169).

Bem diferentes (mais simples, menos elaboradas) são as características do gravado em Evangelhos e epístolas, publicado no Porto em 1497. Mas também aqui há nota de uma ligação peninsular, neste caso adaptando-se, no Porto, texto e imagens de uma edição de Salamanca de 1493 (cf. Anselmo, ibidem, pp.172-173).

Para perceber a presença da imagem nos livros, será necessário, assim, seguir um conjunto de nomes e como evoluem os recursos técnicos. Mas interessa-nos ainda mais as transformações que se operam nos conceitos, aquilo que eles procuram identificar, o que numa publicação torna possível que se fale de "livro", de que elementos é constituído, ou o que leva a que uma publicação seja procurada e apreciada. Ou o que, sendo inexistente ou extraordinário num dado momento, é indispensável num outro, as separações gráficas, os índices, a arrumação das páginas, incluindo a sua identificação. Interessa-nos ainda como essas mudanças correspondem a transformações nas formas de relacionamento com o leitor que envolvem também a iconografia, seja a que separa capítulos, a que fecha o volume, a que torna singular uma folha de rosto, ou a que acompanha os textos. Note-se que a função de separar ou de sublinhar passagens não é excusiva de tarjas e capitulares. Voltando ao Vespesiano, cinco dos ricos desenhos que contam a história em imagens aparecem repetidos ao longo do texto, dois deles quatro vezes. O que aparentemente é a mesma imagem (ou o mesmo tipo de imagem) ganha sentidos diferentes de acordo com a forma e o tempo da sua publicação.

Nas imagens procuramos quem as faz e quem as vê, ou seja, quem lhes dá sentido e organiza ou determina os conceitos referidos atrás. De quem são os desenhos que circulam? Quem os reconhece? Quem grava é alguém que simultaneamente procura e produz imagens. A oficina terá a propriedade das placas onde os desenhos estão conservados. Por isso, conhecer os desenhos é também conhecer a oficina e como evolui. Reproduzem-se motivos, mas as placas são únicas e individualizáveis. Copia-se, mas nas imagens ficam inscritos traços, sinais de gestos concretos que fazem de cada gravura um caso distinto, diferenciável de todos os outros, como a cópia manuscrita se distingue da cópia industrial.

Por exemplo, as diferenças evidentes da gravura da folha de rosto da primeira edição de Os Lusíadas, em 1572, deram azo a muitas explicações, a mais atraente das quais, perfilhada por Aquilino Ribeiro, era de que se estava perante uma contrafacção. A 
inversão da posição do pelicano e as diferenças no plinto podiam significar a abertura de nova gravura a partir de decalque. Hoje sabemos, seja pelo confronto de três dezenas de exemplares que existem espalhados pelo mundo, feito por K. David Jackson (Camões and the first edition of The Lusiads, 1572, Univ. Massachusetts Dartmouth, 2003), seja pelo melhor conhecimento de como decorria um processo de impressão, com modificações constantes sem que se desaproveitasse o que já estava impresso, que existe apenas uma edição com muitas pequenas alterações. A folha de rosto e as suas gravuras são, assim, um exemplo, não da transferência de oficina, mas de um segundo momento da feitura de uma impressão.

Outro exemplo da singularidade do impressor é a forma como, no início da sua actividade, em finais do século XVI, Pedro Craesbeeck, não possuindo ricas capitulares, usava pequenas tarjas envolvendo maiúsculas normais para as substituir, o que constitui uma marca que o identifica. Este tipo de atenção permite que, numa circunstância em que não se conhece o impressor, se perceba a quem pertence um gravado.

Uma imagem pode permitir identificar uma contrafacção, como mostrou Teresa Payan Martins na sua tese, Livros clandestinos e contrafacções em Portugal no século XVIII (FCSH, 1995), onde se percebe que impressores associados aos poderes políticos e religiosos participam, por razões várias, nomeadamente de ordem comercial, no mundo da circulação clandestina.

Uma imagem revela o impressor que se queria discreto, mas mostra também a relação entre oficinas, as placas que circulam, ou as famílias que se sucedem, quem garante a continuidade de um património (em tipos e gravuras). As imagens podem ainda dar uma dimensão do sucesso de uma publicação, como mostra Paulo A. Fonseca ao fazer um apanhado das diferenças que se detectam nos mesmos fascículos da Academia dos Humildes e Ignorantes, sobretudo nos seus primeiros anos de existência, entre $1758 \mathrm{e}$ 1760, diferenças que permitem verificar a multiplicação rápida de edições de um periódico, por vários impressores. Essa multiplicação revela-se em dois tempos. A que se faz no momento em que o fascículo se esgota e é procurado, a um ritmo semanal. A que se faz para completar compilações anuais que se vendem também com sucesso. Uma como outra são localizáveis pelas datas impressas, mas também em parte através das gravuras que identificam os impressores, e que se repetem noutras publicações das mesmas oficinas.

Já Pierre-Antoine Quillard, aqui apresentado por Nuno Saldanha na sua obra de gravador, é um artista de transição, mais conhecido como pintor, mas responsável por gravuras identificáveis, em livros e em grande formato.

Deste facto decorre o que apenas aparentemente seria uma contradição. Ao longo da história das imagens, o seu carácter único não se confunde com a busca da originalidade do que se desenha, mas é relevante como informação sobre um momento de um processo, de um fazer artesanal. Ou seja, olhamos para as imagens nos livros anteriores ao século XIX como elementos de cadeias de imagens que as oficinas reproduzem e não tanto pelo valor que uma mão mais criativa acrescenta e que, mais tarde, permitirá a distinção pela busca da originalidade. A noção de unicidade só implica contradição se não se entender aquilo a que se refere, se falamos do produto enquanto resultado artístico ou do exemplar concreto manufacturado. Este é único, ainda que reproduzindo ou copiando, não se confundindo com objectos que se pretendem inimitáveis enquanto concepção. Neste caso, enquanto sobressai uma 
composição, ou um desenho, o trabalho do gravador, integrado em séries, pode ficar oculto pela qualidade técnica do impresso.

Desta aparente contradição resulta que as perguntas que se fazem e o que se pode retirar das imagens varia segundo os tempos e as circunstâncias. Que problemas se podem, então, colocar?

Um é o que segue os encontros e os desencontros de texto e imagem num mesmo livro, que podem remeter para diferenças de narrativas ou para formas de circulação separadas que circunstancialmente se encontram numa tipografia. Ou seja, o gravado não foi realizado a partir da leitura do mesmo texto. Pode até ser anterior e tem, em qualquer caso, uma existência própria que se encontra circunstancialmente num livro. É essa divergência (e essa autonomia) que o estudo de Fr. António Almeida, a partir da análise da edição de 1513 do Flos Sanctorum, aborda.

Outro problema é o da forma como se relacionam suportes diversificados das representações, transmitindo-se modelos, cruzando sucessivamente, sem uma ordem pré-definida, pintura, gravura, azulejo ou escultura, por exemplo, e fazendo algumas imagens viajar milhares de quilómetros. Nestes circuitos, a fixação de imagens em suportes estáveis pode ser apenas um momento da sua circulação. Painéis pintados inspiram gravadores, do mesmo modo que artistas recorrem a gravuras para compor os seus trabalhos. Di-lo Vítor Serrão a propósito de pinturas de uma igreja alentejana e Sandra Costa mostrando a forma como no azulejo, mas também na pedra esculpida, se recorre às gravuras como fonte de inspiração para representar a vida de Santa Teresa de Jesus, em Lisboa. Outros estudos recentes procuraram precisamente seguir as mesmas pistas. São os casos dos estudos aprofundados de Manuel Batoréo, que comprova a extensão da presença da imagem gravada pela sua apropriação pela pintura em todo o país e o de Ana Paula Correia sobre a relação entre azulejo e gravura, ambos referidos por Vítor Serrão.

Diferentes são as abordagens da imagem em livros do século XX. Apresentamos dois exemplos diametralmente opostos, não apenas no imaginário que convocam, mas também na pretensão de originalidade e de diálogo criativo com o texto que acompanham. Um caso de propaganda, nos manuais escolares, ao lado de exemplos de recriação artística de um texto literário. A estratégia de convencimento de que fala Vítor Serrão para o século XVII não se confunde com a propaganda do século XX sobre que escreve Filipe Serra. E o artista, o editor e o escritor protagonistas do estudo de Liliana Carvalho não existiam antes do século XIX.

Não se pretende, nas páginas que se seguem, colocar todas as perguntas possíveis à iconografia do impresso, ou aos modos como as imagens coexistem com os textos, nos livros. Mas, como terá ficado claro, justifica-se o interesse de um projecto que se reclama de história das ideias pelo estudo de imagens desenhadas e gravadas. Ao contrário do que seria a perspectiva de uma Susan Sontag, agastada pelo menosprezo que a preocupação de interpretar teria pelas formas, o que nos interessa é o sentido das próprias formas, o que representam em cada momento em que se constituem. 0 que implica que não se trata de interpretar para além das formas, mas com elas, e por elas. 


\section{AUTOR}

\section{JOÃO LUÍS LISBOA}

\section{CHC UNL.}

Professor na FCSH, UNL. Director do CHC UNL onde é responsável pelo projecto "Livro e leitura". Publicou, entre outros trabalhos, Teoria da história em Francisco Manuel de Melo (com Teresa Amado) [1983], Ciência e política. Ler nos finais do Antigo Regime (1991), Gazetas. A informação política nos finais do Antigo Regime (coord.) (2002) e, com Tiago C.P. dos Reis Miranda e Fernanda Olival, Gazetas manuscritas da Biblioteca Pública de Évora, 2 vols., 2002 e 2005. 